\title{
An alternative mechanism of pile failure in liquefiable deposits during earthquakes
}

\author{
S. BHATTACHARYA*, S. P. G. MADABHUSHI† and M. D. BOLTON†
}

\begin{abstract}
This paper proposes an alternative mechanism of pile failure in liquefiable deposits during earthquakes. This failure mechanism, based on pile buckling, is formulated by back-analysing 14 case histories of pile foundation performance during earthquakes and verified using dynamic centrifuge tests. A new parameter, the slenderness ratio of a pile, is introduced to classify pile performance in liquefiable soils. This parameter fits very well both the reported case histories and the centrifuge test results.
\end{abstract}

KEYWORDS: piles; failure; case history; centrifuge modelling; liquefaction
Cet exposé propose un autre mécanisme de défaillance pour les piles dans des dépôts liquéfiables pendant les tremblements de terre. Ce mécanisme de défaillance, basé sur la flexion de la pile, est formulé par une rétro analyse de 14 rapports des performances de fondations à piles pendant les séismes ; et ce mécanisme est vérifié en utilisant des essais centrifuges dynamiques. Un nouveau paramètre, le taux de minceur de la pile, est introduit pour qualifier la performance des piles dans des sols liquéfiables. Ce paramètre s'accorde très bien avec les histoires de cas rapportées et les résultats des essais centrifuges.

\section{INTRODUCTION}

Current understanding of buckling of piles

Buckling of piles is currently considered in design under the following headings (Fleming et al., 1992):

(a) during installation by driving, especially of an unsupported pile

(b) partially exposed piles, as in jetties or offshore platforms

(c) piles in very soft clay.

Studies have shown that piles founded in soft clay can fail by buckling (e.g. Bergfelt, 1957; Brandtzaeg \& Elvegaten, 1957; Golder \& Skipp, 1957). In this regard Eurocode 7 (1997) suggests that

Slender piles passing through water or thick deposits of very weak soil need to be checked against buckling. This check is not normally necessary when piles are completely embedded in the ground unless the characteristic undrained shear strength is less than $15 \mathrm{kPa}$.

The problem of buckling of fully embedded piles has been investigated by Granholm (1929), Davisson \& Robinson (1965), and Reddy \& Valsangkar (1970). The analysis shows that buckling will be confined to a critical length of the pile depending on the relative stiffness of the pile and the soil.

The purpose of this paper is to establish that fully embedded end-bearing piles passing through saturated, loose to medium dense sands and resting on a hard layer can buckle under the action of axial load alone if the surrounding soil liquefies in an earthquake. The stress in the pile section will initially be within the elastic range, and the buckling length will be the entire length of pile in liquefied soil. Lateral loading, due to slope movement, inertia, or outof-straightness, will increase lateral deflections, which in turn can cause plastic hinges to form, reducing the buckling load, and promoting more rapid collapse. These lateral load

Manuscript received 8 October 2002; revised manuscript accepted 10 December 2003.

Discussion on this paper closes 1 October 2004, for further details see p. ii.

* Fugro Limited (UK); previously Department of Engineering, University of Cambridge.

$\dagger$ Department of Engineering, University of Cambridge. effects are, however, secondary to the basic requirement that piles in liquefiable soils must be checked against Euler's buckling.

\section{Current design of piles in liquefiable soils}

In contrast, all expert opinion has previously regarded the failure of piles in liquefiable soil during an earthquake as being due exclusively to the drag on the pile accompanying lateral spreading of liquefied soil (NRC, 1985; Hamada, 1992a, 1992b; Tokimatsu et al., 1996, 1997, 1998; Ishihara, 1997; Goh \& O’Rourke, 1999; Abdoun \& Dobry, 2002; Finn $\&$ Fujita, 2002). This unanimity has led the Japanese Code of Practice (JRA, 1996), for example, to overlook considerations of axial buckling in favour of calculations of bending moments due to lateral spreading. Other codes, such as the USA code (NEHRP, 2000) and Eurocode 8 (1998) part 5, also focus on bending strength and omit considerations of the bending stiffness required to avoid buckling in the event of soil liquefaction. We aim, through an analysis of case histories and centrifuge model tests, to show that these codes of practices are inadequate, and that buckling need to be addressed.

\section{STUDY OF CASE HISTORIES}

Structurally, axially loaded piles are long slender columns with lateral support from the surrounding soil. If unsupported, these columns could fail in buckling instability and not as a result of crushing of the pile material. Fig. 1 shows the length and diameter of tubular piles used in different projects around the world, following Bond (1989). The figure shows that piles normally have ratios of length to diameter of 25 to 100 . In this paper we shall introduce the parameter $r_{\text {min }}$ (minimum radius of gyration) to analyse the piles in the reported case histories and centrifuge tests. This parameter can represent piles of any shape (square, tubular or circular), and is used by structural engineers for studying buckling instability.

$$
I=A r_{\min }^{2} \text { or } r_{\min }=\sqrt{\frac{I}{A}}
$$

where $I$ is the second moment area of the pile section about the weakest axis $\left(\mathrm{m}^{4}\right), A$ is the area of the pile section $\left(\mathrm{m}^{2}\right)$, 


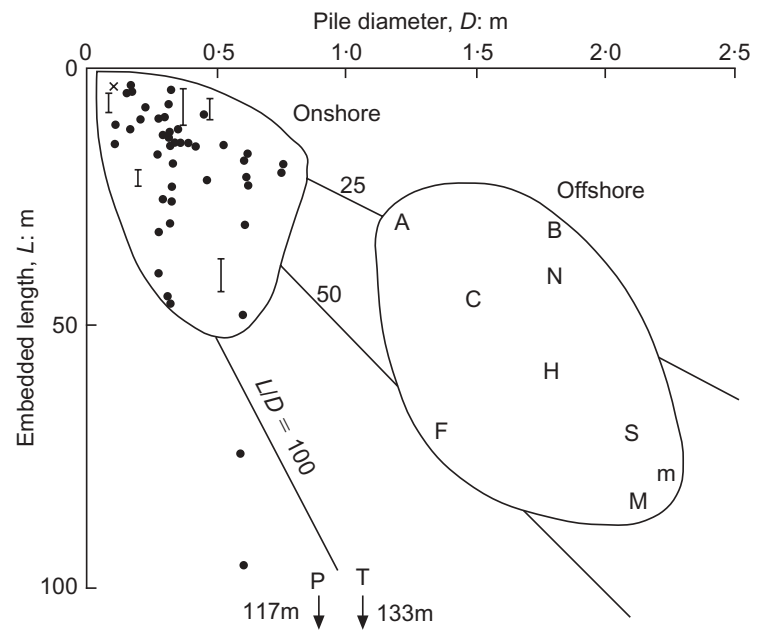

Fig. 1. Length and diameter of tubular piles (Bond, 1989)

and $r_{\min }$ is the minimum radius of gyration of the pile section about any axis of bending $(\mathrm{m})$. For a tubular pile $r_{\min }$ is 0.35 times the outside diameter, and hence from Fig. 1 the length $(L)$ to $r_{\min }$ ratio of normal piles ranges from 71 to 284 .

A significant number of cases of pile performance during earthquake liquefaction have been reported in the literature. Some pile foundations were found to survive the earthquake, whereas others suffered severe damage. Fourteen cases of pile foundation performance are analysed and presented in Table 1, giving emphasis to buckling characteristics. The parameters in the analysis are:

(a) $L_{\text {eff }}$, the effective length of the pile in the liquefiable region. The definition of effective length shown in Fig. 2 has been adopted from column stability theory, and is chosen to normalise the different boundary conditions of pile tip and pile head. $L_{\text {eff }}$ is also familiar as the Euler's buckling length of a strut pinned at both ends. In practice, designers may prefer to extend the effective length by a few diameters to account for imperfect fixity in the non-liquefying layer (e.g. Fleming et al., 1992).

(b) $r_{\min }$, the minimum radius of gyration of the pile.

(c) The slenderness ratio of the pile in the liquefiable region, $L_{\text {eff }} / r_{\text {min. }}$.

(d) The allowable load on the pile, $P$, based on conventional design procedures, with no allowance for liquefaction.

(e) Euler's elastic critical load of the pile, $P_{\mathrm{cr}}$, calculated from the well-known buckling formula:

$$
P_{\text {cr }}=\frac{\pi^{2}}{L_{\text {eff }}^{2}} E I
$$

( $f$ ) The axial stress, $\sigma$, in the pile, calculated by dividing $P$ by the cross-sectional area of the pile, $A$. The value at failure is written as $\sigma_{\mathrm{f}}$.

Figure 3 shows the effective length of the piles in a liquefiable zone plotted against the $r_{\min }$ of the pile section. A line representing a slenderness ratio $\left(L_{\mathrm{eff}} / r_{\min }\right)$ of 50 is drawn, which distinguishes poor-performance piles from the good ones. This line is of significance in structural engineering, as it is often used to distinguish between 'long' and 'short' columns. Columns having slenderness ratios below 50 are expected to fail in crushing, whereas those above 50 are expected to fail in bending due to buckling instability.

Figure 4 shows the plot of 12 concrete piles mentioned in Table 1. The piles are assumed to be of M25 grade concrete (BSI, 1985), with a characteristic strength of $25 \mathrm{MPa}$. In the plot, three well-defined lines are drawn:

(a) The yield stress line $\left(\sigma_{\mathrm{y}}=11.2 \mathrm{MPa}\right)$, taken as the design crushing value;

(b) Euler's curve for $\sigma_{\mathrm{cr}}$, given by equation (3), which is

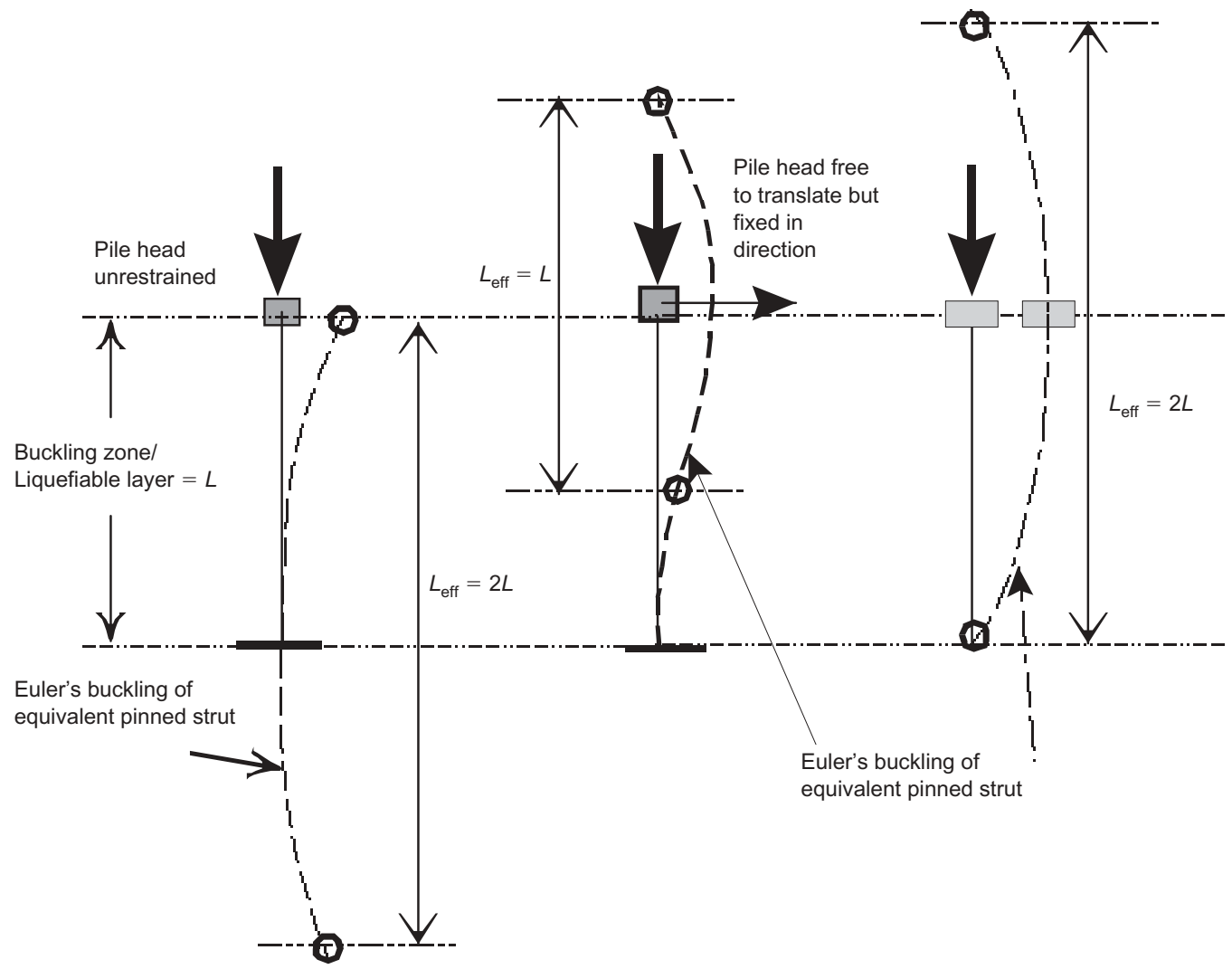

Fig. 2. Concept of effective length of pile 
Table 1. Summary of pile performances

\begin{tabular}{|c|c|c|c|c|c|c|c|c|c|c|c|c|c|}
\hline $\begin{array}{l}\text { S1 } \\
\text { no. }\end{array}$ & Case history and reference & $L: \mathrm{m}$ & $L_{0}: \mathrm{m}$ & $\begin{array}{l}\text { Pile section/ } \\
\text { type }\end{array}$ & $\begin{array}{l}\text { Framing action/ } \\
\beta \text { value }\end{array}$ & $L_{\text {eff }}: \mathrm{m}$ & $r_{\min }: \mathrm{m}$ & $L_{\text {eff }} / r_{\text {min }}$ & $P: \mathrm{MN}$ & $P_{\text {cr }}: \mathrm{MN}$ & $\sigma: \mathrm{MPa}$ & $\begin{array}{l}\text { Lateral spreading } \\
\text { observed? }\end{array}$ & Performance \\
\hline 1 & $\begin{array}{l}\text { 10-storey Hokuriku building, } 1964 \\
\text { Niigata earthquake (Hamada, } \\
\text { 1992a,b) }\end{array}$ & 12 & 5 & $\begin{array}{l}0.4 \mathrm{~m} \text { dia. } \\
\text { RCC }\end{array}$ & $\begin{array}{l}\text { Large piled raft } \\
\text { with basement } \\
1\end{array}$ & $5 \cdot 0$ & $0 \cdot 1$ & 50 & 0.77 & $12 \cdot 4$ & $6 \cdot 2$ & $\begin{array}{l}\text { Yes, nearby ground } \\
\text { moved by } 2 \mathrm{~m}\end{array}$ & Good \\
\hline 2 & $\begin{array}{l}\text { Landing bridge, 1987. Edgecumbe } \\
\text { earthquake (Berrill et al., 2001) }\end{array}$ & 9 & 4 & $\begin{array}{l}0.4 \mathrm{~m} \text { square } \\
\text { PSC }\end{array}$ & $\begin{array}{l}\text { Raked piles, no sway } \\
\text { frame } \\
0.5\end{array}$ & $2 \cdot 0$ & $0 \cdot 12$ & 17 & 0.62 & 139 & $3 \cdot 8$ & $\begin{array}{l}\text { Yes, ground cracked } \\
\text { and sand ejected }\end{array}$ & Good \\
\hline 3 & $\begin{array}{l}\text { 14-storey building in American } \\
\text { park, } 1995 \text { Kobe earthquake } \\
\text { (Tokimatsu et al., 1996) }\end{array}$ & 33 & 11 & $\begin{array}{l}2.5 \mathrm{~m} \text { dia. } \\
\text { RCC }\end{array}$ & $\begin{array}{l}\text { Large pile group and } \\
\text { large pile dia. } \\
1.0\end{array}$ & 11 & 0.63 & 19 & 18 & 3915 & $3 \cdot 8$ & $\begin{array}{l}\text { Yes, quay walls on } \\
\text { the west, south and } \\
\text { east moved. } \\
\text { However, the piles } \\
\text { probably did not } \\
\text { experience lateral } \\
\text { spreading forces } \\
\text { due to deep } \\
\text { cement mixing } \\
\text { walls }\end{array}$ & Good \\
\hline 4 & $\begin{array}{l}\text { Kobe Shimim hospital, } 1995 \\
\text { Kobe earthquake (Soga, 1997) }\end{array}$ & 30 & $6 \cdot 2$ & $\begin{array}{l}0.66 \mathrm{~m} \text { dia. } \\
\text { steel tube }\end{array}$ & $\begin{array}{l}\text { Large piled raft with } \\
\text { basement. } \\
1 \cdot 0\end{array}$ & $6 \cdot 2$ & 0.23 & 27 & $3 \cdot 0$ & 91 & $92 \cdot 6$ & $\begin{array}{l}\text { No, ground } \\
\text { subsided. }\end{array}$ & Good \\
\hline 5 & $\begin{array}{l}\text { Hanshin expressway pier, } 1995 \\
\text { Kobe earthquake (Ishihara, 1997) }\end{array}$ & 41 & $15 \cdot 9$ & $\begin{array}{l}1.5 \mathrm{~m} \text { dia. } \\
\text { RCC }\end{array}$ & $\begin{array}{l}\text { Small group } \\
(22 \text { piles }) \\
1 \cdot 0\end{array}$ & $15 \cdot 9$ & 0.38 & 42 & 14 & 305 & $7 \cdot 9$ & $\begin{array}{l}\text { Yes, ground } \\
\text { movement of } \\
0.62 \mathrm{~m}\end{array}$ & Good \\
\hline 6 & $\begin{array}{l}\text { LPG tank 101, Kobe earthquake } \\
\text { Ishihara (1997) }\end{array}$ & 27 & 15 & $\begin{array}{l}1 \cdot 1 \mathrm{~m} \text { dia. } \\
\text { RCC }\end{array}$ & $\begin{array}{l}\text { Large piled raft } \\
1.0\end{array}$ & 15 & $0 \cdot 28$ & 53 & $4 \cdot 1$ & 79 & $4 \cdot 3$ & $\begin{array}{l}\text { Yes, ground } \\
\text { moved by } 0.7 \mathrm{~m}\end{array}$ & Good \\
\hline 7 & $\begin{array}{l}\text { NHK building, } 1964 \text { Niigata } \\
\text { earthquake (Hamada, 1992a,b) }\end{array}$ & 12 & $9 \cdot 3$ & $\begin{array}{l}0 \cdot 35 \mathrm{~m} \text { dia. } \\
\text { RCC }\end{array}$ & $\begin{array}{l}\text { Groups tied by } \\
\text { flexible beam. Less } \\
\text { embedment at } \\
\text { pile tip } \\
2 \cdot 0\end{array}$ & $18 \cdot 6$ & $0 \cdot 09$ & 207 & 0.43 & $0 \cdot 52$ & $4 \cdot 4$ & $\begin{array}{l}\text { Yes, nearby ground } \\
\text { moved by } 2 \mathrm{~m} \text {, and } \\
\text { it is near to the } \\
10 \text {-storey building } \\
\text { in case history } 1 .\end{array}$ & Poor \\
\hline 8 & $\begin{array}{l}\text { NFCH building, } 1964 \text { Niigata } \\
\text { earthquake (Hamada, 1992a,b) }\end{array}$ & 9 & 7 & $\begin{array}{l}0 \cdot 35 \mathrm{~m} \text { dia. } \\
\text { RCC } \\
\text { Hollow }\end{array}$ & $\begin{array}{l}\text { Groups tied by } \\
\text { flexible } \\
\text { beam. Less embedment } \\
\text { at pile tip } \\
2 \cdot 0\end{array}$ & 14 & $0 \cdot 10$ & 140 & $0 \cdot 29$ & $0 \cdot 82$ & $4 \cdot 5$ & $\begin{array}{l}\text { Yes, nearby ground } \\
\text { moved by } 1-2 \mathrm{~m}\end{array}$ & Poor \\
\hline 9 & $\begin{array}{l}\text { Showa bridge, } 1964 \text { Niigata } \\
\text { earthquake (Hamada, 1992a,b) }\end{array}$ & 25 & 19 & $\begin{array}{l}0.6 \mathrm{~m} \text { dia. } \\
\text { steel tube }\end{array}$ & $\begin{array}{l}\text { A single row of piles } \\
2 \cdot 0\end{array}$ & 38 & $0 \cdot 21$ & 181 & 0.96 & $1 \cdot 10$ & $56 \cdot 3$ & $\begin{array}{l}\text { Yes, width of river } \\
\text { decreased. }\end{array}$ & Poor \\
\hline 10 & $\begin{array}{l}\text { Yachiyo Bridge, } 1964 \text { Niigata } \\
\text { earthquake (Hamada, 1992a,b) }\end{array}$ & 11 & 8 & $\begin{array}{l}0 \cdot 3 \mathrm{~m} \text { dia. } \\
\text { RCC }\end{array}$ & $\begin{array}{l}\text { Isolated footing } \\
2 \cdot 0\end{array}$ & 16 & 0.08 & 200 & $0 \cdot 34$ & 0.39 & $4 \cdot 8$ & $\begin{array}{l}\text { Yes, width of river } \\
\text { decreased }\end{array}$ & Poor \\
\hline 11 & $\begin{array}{l}\text { Gaiko Warehouse, } 1983 \text { Chubu } \\
\text { earthquake (Hamada, 1992a,b) }\end{array}$ & 18 & 14 & $\begin{array}{l}0 \cdot 6 \mathrm{~m} \text { dia. } \\
\text { PSC. } \\
\text { Hollow }\end{array}$ & $\begin{array}{l}\text { Isolated footing } \\
2 \cdot 0\end{array}$ & 28 & $0 \cdot 16$ & 175 & 1.47 & $1 \cdot 61$ & $9 \cdot 3$ & $\begin{array}{l}\text { Yes, nearby ground } \\
\text { moved by } 1.5 \mathrm{~m}\end{array}$ & Poor \\
\hline 12 & $\begin{array}{l}\text { 4-storey fire house, } 1995 \text { Kobe } \\
\text { earthquake (Tokimatsu et al., } \\
\text { 1996) }\end{array}$ & 30 & $16 \cdot 4$ & $\begin{array}{l}0 \cdot 4 \mathrm{~m} \text { dia. } \\
\text { PSC }\end{array}$ & $\begin{array}{l}\text { Groups tied by beam, } \\
\text { large embedment } \\
1 \cdot 0\end{array}$ & $16 \cdot 4$ & $0 \cdot 10$ & 161 & 0.89 & $1 \cdot 15$ & $7 \cdot 0$ & $\begin{array}{l}\text { Yes, building } \\
\text { moved and tilted } \\
\text { towards the sea }\end{array}$ & Poor \\
\hline
\end{tabular}




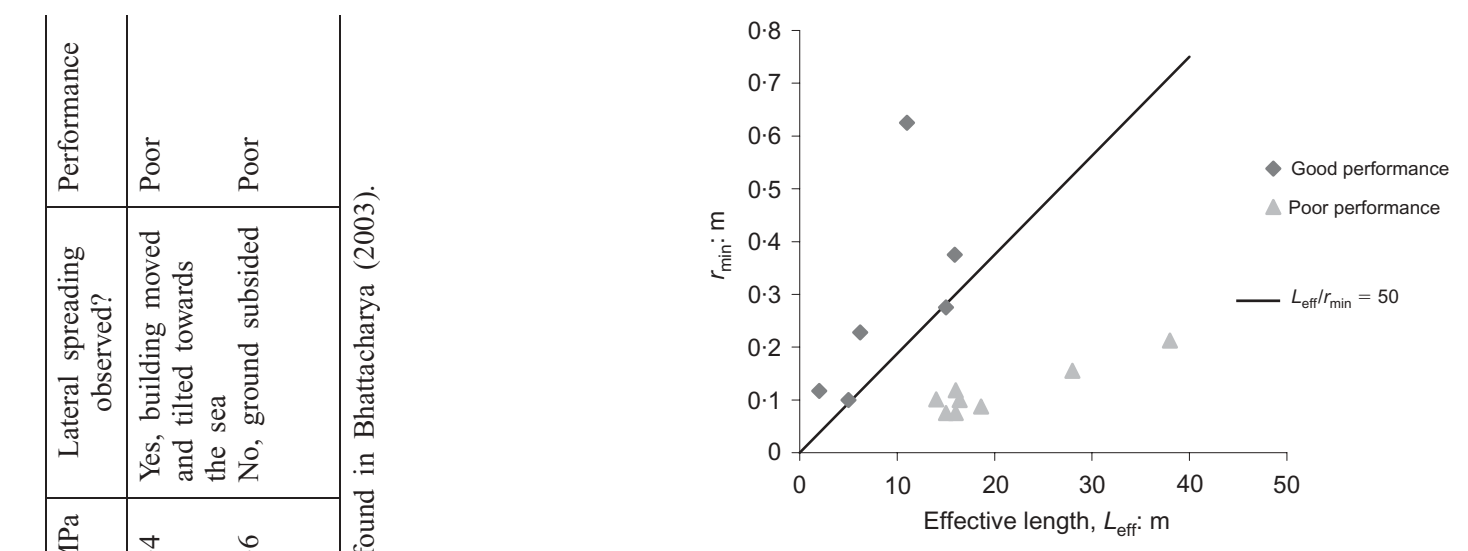

Fig. 3. $L_{\text {eff }}$ against $r_{\min }$ for piles studied

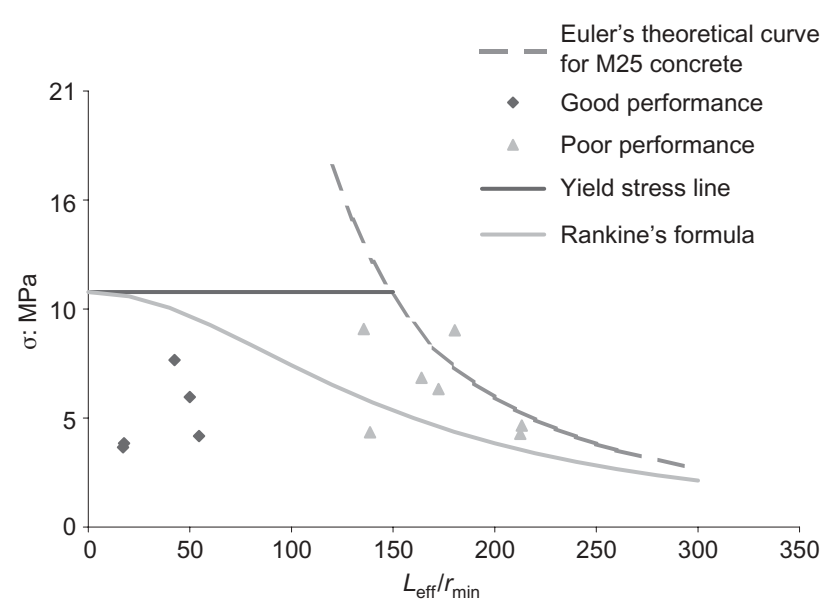

Fig. 4. Plot of concrete pile performance mentioned in Table 1

the elastic stability limit obtained by substituting the value of $I$ from equation (1) into equation (2) and noting that $\sigma_{\mathrm{cr}}$ is the critical stress given by $\left(P_{\mathrm{cr}} / A\right)$

$$
\sigma_{\mathrm{cr}}=\frac{P_{\mathrm{cr}}}{A}=\frac{\pi^{2}}{\left(L_{\mathrm{eff}} / r_{\mathrm{min}}\right)^{2}} E
$$

(c) a curve for $\sigma_{\mathrm{f}}$ drawn using Rankine's (1866) formula, shown by equation (4). This design curve mediates the transition between strength and stability. Many other similar curves, such as Perry (1886) and Robertson (1925), can equally be used.

$$
\frac{1}{\sigma_{\mathrm{f}}}=\frac{1}{\sigma_{\mathrm{cr}}}+\frac{1}{\sigma_{\mathrm{y}}}
$$

where $\sigma_{\mathrm{y}}$ is the yield stress of the material, and $\sigma_{\mathrm{cr}}$ is the elastic critical stress as calculated by equation (3), leading to an estimate of the combined failure stress, $\sigma_{\mathrm{f}}$.

\section{HYPOTHESIS ARISING FROM THE STUDY OF CASE HISTORIES}

The study of the case histories seems to show a dependence of pile performance on buckling parameters. As short columns fail in crushing and long columns in buckling, the analysis suggests that pile failure in liquefied soils is similar in some ways to the failure of long columns in air. The lateral support offered to the pile by the soil prior to the earthquake is removed during liquefaction. This hypothesis is shown in Fig. 5 and explained below.

During earthquakes, soil layers overlying the bedrock are 


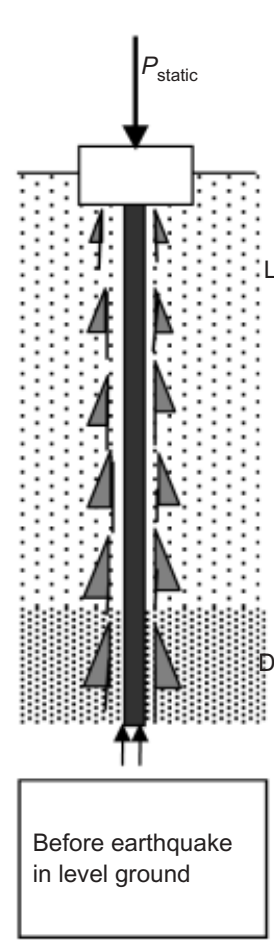

(a)

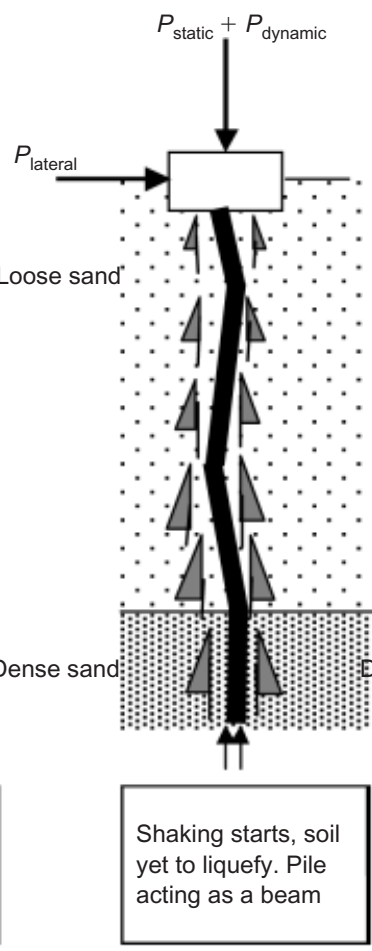

(b)

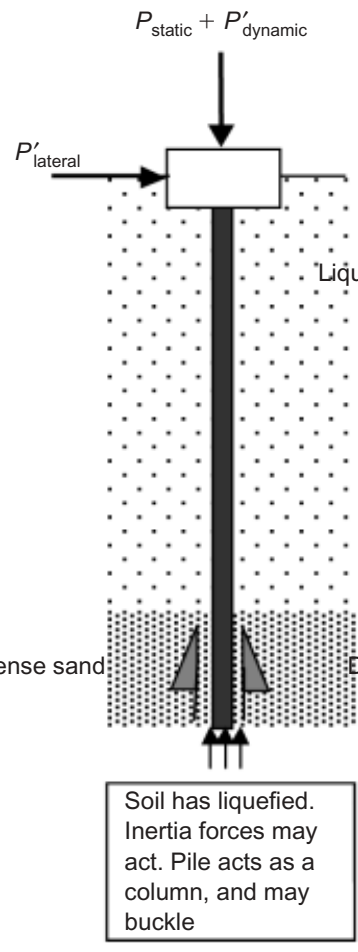

(c)

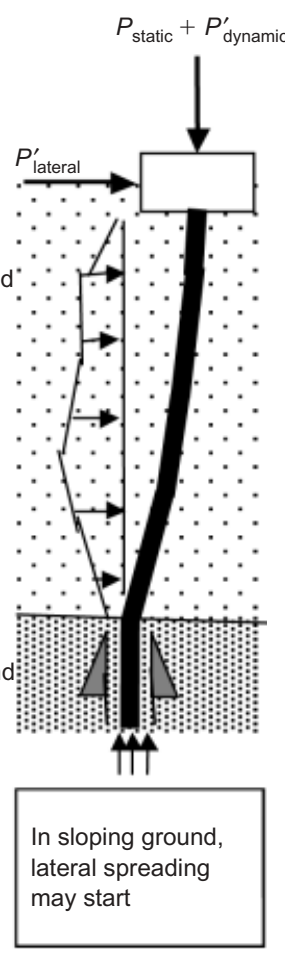

(d)

Fig. 5. Time history of loading in proposed failure mechanism

subjected to seismic excitation consisting of numerous incident waves, namely shear (S) waves, dilatational or pressure $(\mathrm{P})$ waves, and surface (Rayleigh and Love) waves, which result in ground motion. The ground motion at a site will depend on the stiffness characteristics of the layers of soil overlying the bedrock. This motion will also affect a piled structure. As the seismic waves arrive in the soil surrounding the pile, the soil layers will tend to deform. This seismically deforming soil will try to move the piles and the embedded pile-cap with it. Subsequently, depending upon the rigidity of the superstructure and the pile-cap, the superstructure may also move with the foundation.

The pile may thus experience two distinct phases of initial soil-structure interaction:

(a) Before the superstructure starts oscillating, the piles may be forced to follow the soil motion, depending on the flexural rigidity $(E I)$ of the pile. Here the soil and pile may take part in kinematic interplay, and the motion of the pile may differ substantially from the free field motion. This may induce bending moments in the pile.

(b) As the superstructure starts to oscillate, inertial forces are generated. These inertial forces are transferred as lateral forces and overturning moments to the pile via the pile-cap. The pile-cap transfers the moments as varying axial loads and bending moments in the piles. Thus the piles may experience additional axial and lateral loads, which cause additional bending moments in the pile.

These two effects occur with only a small time lag. If the section of the pile is inadequate, bending failure may occur in the pile. The behaviour of the pile at this stage may be approximately described as a beam in an elastic foundation, where the soil provides sufficient lateral restraint. The available confining pressure around the pile is not expected to decrease substantially in these initial phases. The response to changes in axial load in the pile would not be severe either, as shaft resistance continues to act. This is shown in Fig. 5(b).

In loose saturated sandy soil, as the shaking continues, pore pressure will build up and the soil will start to liquefy. With the onset of liquefaction, an end-bearing pile passing through liquefiable soil will experience distinct changes in its stress state.

(a) The pile will start to lose its shaft resistance in the liquefied layer and shed axial loads downwards to mobilise additional base resistance. If the base capacity is exceeded, settlement failure will occur.

(b) The liquefied soil will begin to lose its stiffness so that the pile acts as an unsupported column, as shown in Fig. 5(c). Piles that have a high slenderness ratio will then be prone to axial instability, and buckling failure may occur in the pile, enhanced by the actions of lateral disturbing forces and also by the deterioration of bending stiffness due to the onset of plastic yielding.

In sloping ground, even if the pile survives the above load conditions, it may experience additional drag load due to the lateral spreading of soil. Under these conditions, the pile may behave as a beam-column (column with lateral loads): see Fig. 5(d).

\section{DYNAMIC CENTRIFUGE MODELLING AND MODEL \\ LAYOUT}

Dynamic centrifuge modelling is regarded as an appropriate tool to test the new hypothesis of pile failure irrespective of lateral drag. The $10 \mathrm{~m}$ beam centrifuge at the Schofield Centre, Cambridge University Engineering Department (CUED), was used to perform the centrifuge tests. Details of the centrifuge and the applicable scaling laws can be found in Schofield (1980) and Schofield (1981). A mechanical shaking table, known as the stored angular momentum (SAM) earthquake actuator, developed at Cambridge University 
(Madabhushi et al., 1998) was used to impart in-flight earthquake loading to the physical models.

In a full-scale structure, piled foundations rest within a soil that is unbounded laterally. In order to simulate an analogous situation in the centrifuge model, a specially designed model container known as the ESB (equivalent shear beam) box has been used. The container has inside dimensions of $560 \mathrm{~mm} \times 235 \mathrm{~mm} \times 220 \mathrm{~mm}$ (deep), and its boundary wall is designed to have the same dynamic stiffness as that of unliquefied soil in the free field. Details of the design of the box can be seen in Schofield \& Zeng (1992).

Four model tests (SB-02, SB-03, SB-04 and SB-05) were carried out at 1:50 scale and at $50 \mathrm{~g}$ (i.e. at 50 times the earth's gravity) to study the problem of pile failure. Experiments were designed in level ground to avoid the effects of drag due to lateral spreading. The main aim was to study the effect of axial load on a pile as the soil liquefies. Eleven piles were tested in the four tests performed. The model piles were made of dural alloy tube, the properties of which are given in Table 2. The application of scaling laws (Schofield, 1980) would show that a full-scale reinforced concrete pile with an equivalent bending stiffness would have an external diameter of $507 \mathrm{~mm}$ and an internal diameter of $383 \mathrm{~mm}$, typical of driven cast-in-place piles. However, the discussion will be based solely on the behaviour observed in the model at $50 \mathrm{~g}$. A schematic diagram showing the basic principle of the experiments is shown in Fig. 6. A block of brass fixed at the pile head as shown in Fig. 7 is used to simulate the axial load in the pile in all the tests. With the increase in centrifugal acceleration to $\mathrm{Ng}$, the brass weight imposes increasing axial force in the pile, as shown in Fig. 6. One problem of using a brass weight is the action of earth's gravity, by which the resultant load acting on a radial pile is not purely axial. At lower $g$ levels especially, the soil may not gain enough confining pressure to prevent the pile from deflecting under disproportionately large lateral forces, and the experiment may therefore begin by inducing an initial imperfection.

Following Fig. 6, there are three load effects that control the failure mechanism in the centrifuge:

Table 2. Properties of model pile

\begin{tabular}{l|c}
\hline Material & Aluminium alloy (dural) \\
\hline Young's modulus, $E$ & $70 \mathrm{GPa}$ \\
Outside diameter & $9 \cdot 3 \mathrm{~mm}$ \\
& $(9 \cdot 2 \mathrm{~mm}$ in test SB-02) \\
Inside diameter & $8.5 \mathrm{~mm}$ \\
$r_{\text {min of the section }}$ & $3.1 \mathrm{~mm}$ \\
Yield stress (measured) & $250 \mathrm{MPa}$ \\
Plastic moment capacity, $M_{\mathrm{p}}$ & $8175 \mathrm{Nmm}$ \\
$E I$ of the section & $7 \cdot 77 \times 10^{6} \mathrm{~N} \mathrm{~mm}^{2}$ \\
\hline
\end{tabular}

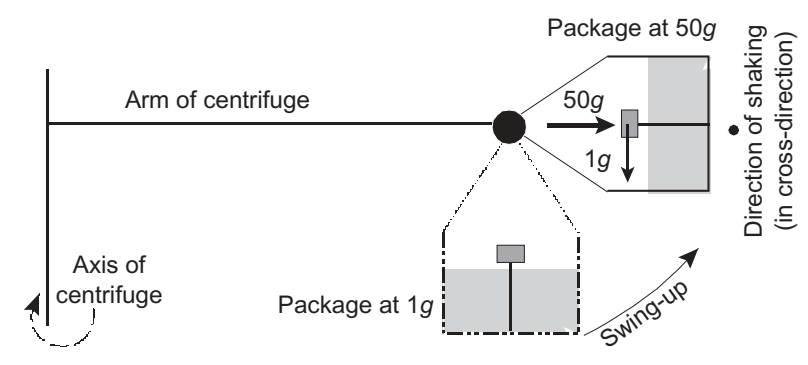

Fig. 6. Forces acting on the model pile

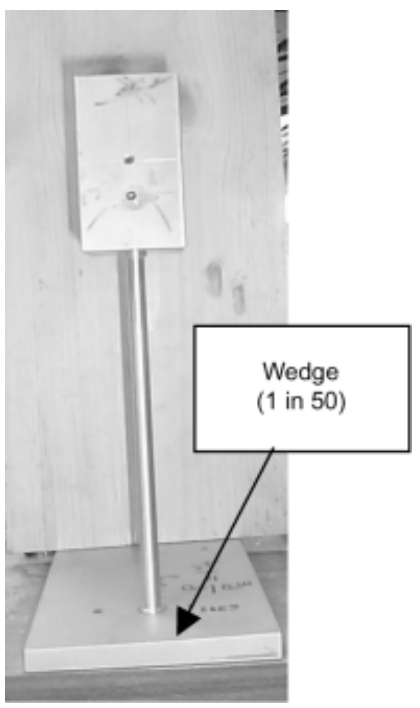

Fig. 7. Method adopted to simulate axial load in pile and to minimise $1 g$ effect

(a) $1 g$ effect of earth's gravity on the pile-head mass

(b) $\mathrm{Ng}$ effect of centrifuging the pile-head mass

(c) inertia force induced during earthquake shaking.

A typical layout of a model is shown in Fig. 8. Table 3 summarises the four tests, stating the parameters involved. Noted that through the sequence of tests the abovementioned loading effects were successfully decoupled. In test SB-02 all three effects were present, whereas in test SB04 only the effect of axial load was studied. The effect of $1 g$ was countered in tests SB-03, SB-04 and SB-05 by fixing the bottom of the pile in a wedge at a slope 1 in 50 , as shown in Fig. 7. This corrects the imperfection in simulated gravity and imposes a purely axial load in the pile at $50 \mathrm{~g}$. In test SB-04 a specially designed frame was used to restrain the head mass against inertial action, as shown in Fig. 9. Thus the pile is only allowed to move in a transverse direction orthogonal to the direction of shaking. Also, although the wedge corrects the $1 g$ effect at $50 g$, at lower $g$ levels the load acting is still not purely axial. So as to avoid premature failure while the $g$ level was being increased, a retractable pneumatic piston was used to hold the head mass temporarily. The pressure in the piston was released when the package reached $50 \mathrm{~g}$, and the pile remained stable. Lateral shaking was then imparted to the model. Test SB-04 was repeated as SB-05, but without soil. Therefore the various influences on pile behaviour could be distinguished.

Fraction E silica sand prepared to a relative density of $45 \%$ was used for each model. Table 4 shows the properties of the sand. To have a consistent scaling law for time in inertial problems featuring pore pressure generation and dissipation, the viscosity of the pore fluid must be scaled up. Silicone oil was used, having a viscosity 50 times that of water.

Miniature instruments such as pore pressure transducers (PPT) and accelerometers (ACC) were buried in the model to obtain the soil response. An earthquake of 0.5 to $0.9 \mathrm{~s}$ duration, $50 \mathrm{~Hz}$ frequency, and of lateral intensity $5 g$, was fired in the tests, which would correspond to $25-45 \mathrm{~s}$ duration of a $1 \mathrm{~Hz}$ frequency earthquake of peak bedrock acceleration $0 \cdot 1 g$ at prototype scale.

In all the tests the models were fully prepared at $1 g$ : thus pile installation effects were not considered. The piles were fixed in place in the ESB box, and sand was poured uniformly in layers by air pluviation from an overhead hopper. After the completion of sand pouring, the model 


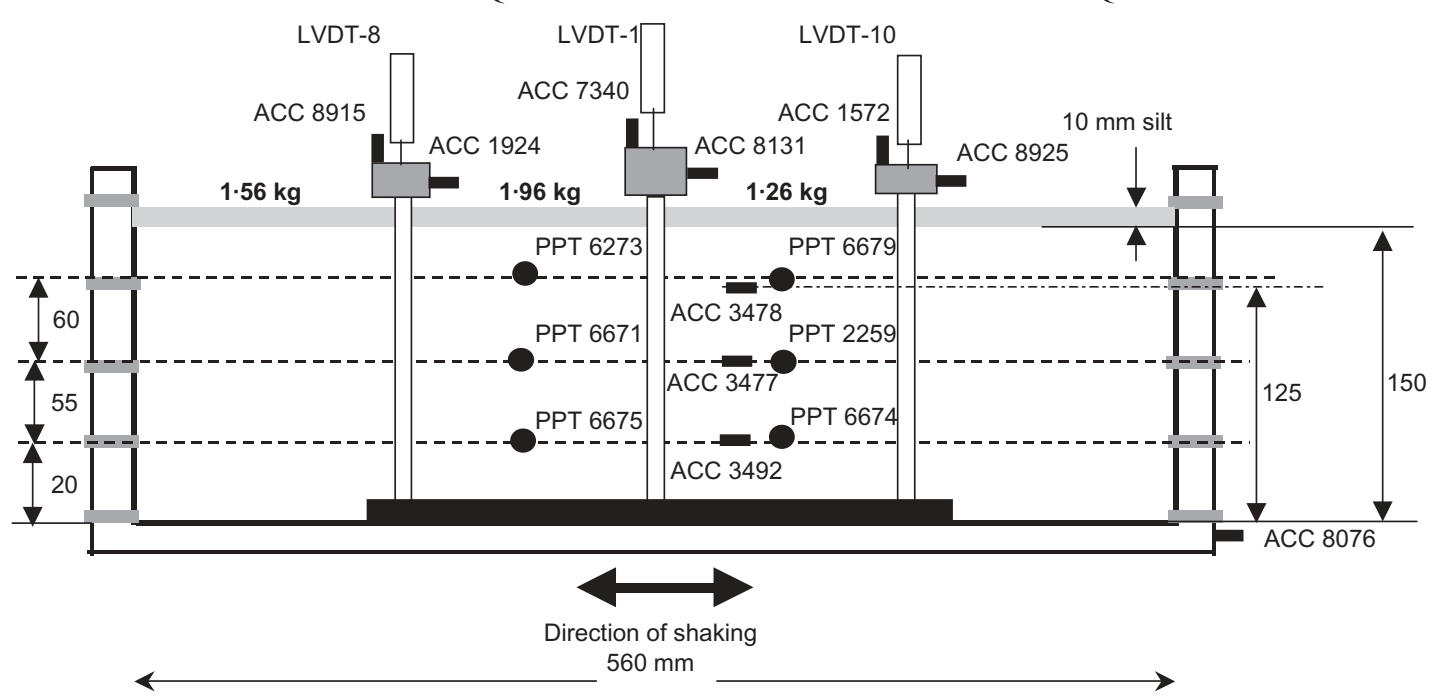

Fig. 8. Model layout and instrumentation in test SB-02

Table 3. Summary of the tests

\begin{tabular}{|c|c|c|}
\hline Test ID & Parameters involved in the test & Remarks \\
\hline $\begin{array}{l}\text { SB-02 } \\
\text { (with soil) } \\
\text { SB-03 } \\
\text { (with soil) } \\
\text { SB-04 } \\
\text { (with soil) } \\
\text { SB-05 } \\
\text { (no soil) }\end{array}$ & $\begin{array}{l}1 g \text { effect, axial load and inertial effects } \\
\text { The effect of axial load and inertia load } \\
\text { Only the effect of axial load } \\
\text { Only the effect of axial load }\end{array}$ & $\begin{array}{l}\text { Two piles failed during } \\
\text { swing-up owing to } 1 g \text { effect } \\
1 g \text { effect removed by wedge } \\
1 g \text { and inertial effects } \\
\text { removed } \\
1 g \text { and inertial effects } \\
\text { removed }\end{array}$ \\
\hline
\end{tabular}

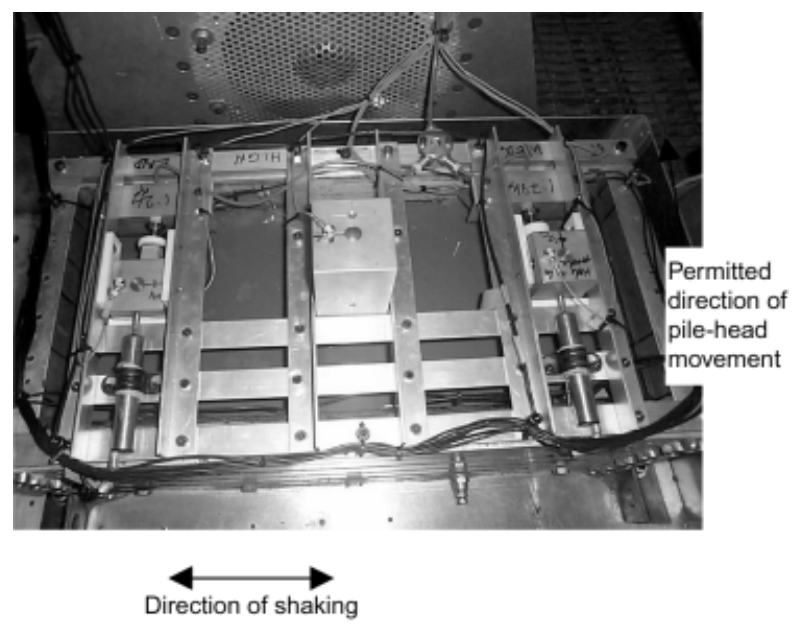

Fig. 9. Test SB-04 with guides to hold the masses against inertia force

Table 4. Properties of Fraction $E$ sand (after Tan, 1990)

\begin{tabular}{l|c}
\hline$D_{10}$ grain size & $0 \cdot 095 \mathrm{~mm}$ \\
$D_{50}$ grain size & $0 \cdot 14 \mathrm{~mm}$ \\
$D_{60}$ grain size & $0 \cdot 15 \mathrm{~mm}$ \\
Specific gravity, $G_{\mathrm{s}}$ & $2 \cdot 65$ \\
Minimum void ratio, $e_{\min }$ & $0 \cdot 613$ \\
Maximum void ratio, $e_{\max }$ & $1 \cdot 014$ \\
Permeability to water $(e=0 \cdot 72)$ & $0.98 \times 10^{-4} \mathrm{~m} / \mathrm{s}$ \\
Angle of shearing resistance at & $32^{\circ}$ (estimated value) \\
critical state, $\phi_{\text {crit }}$ & \\
\hline
\end{tabular}

was fully saturated with silicone oil. The pile-head masses were so designed that the axial loads applied to the piles at $50 \mathrm{~g}$ were arranged around Euler's elastic critical load $\left(P_{\mathrm{cr}}\right)$, assuming the pile to be a long column with the liquefied soil offering no support.

\section{TESTS RESULTS AND ANALYSIS}

Overall pile performance

A summary of the performance of the nine piles in tests SB-02, SB-03 and SB-04 is shown in Table 5. The test results of SB-05 are not included in the table, as the test was identical to SB-04 except that it did not have soil, and it focused only on the buckling of two cantilever struts similar to piles 7 and 8, which failed in SB-04. In the table, $P_{\text {cr }}$ represents the elastic critical load of the pile treated as a column neglecting any support from the soil. It can be seen that, in tests SB-02 and SB-04, all piles that should have failed did fail, whereas the piles in SB-03 should not have failed according to the buckling criterion, and did not fail. Pile failure in SB-02 cannot be positively attributed to the effects of axial load as lateral loads were also applied, whereas in test SB-04 the load was purely axial at failure. It can be concluded that tests SB-03 and SB-04 support the hypothesis of pile failure occurring for $P / P_{\text {cr }} \geqslant 1$. Fig. 10 shows the slenderness ratio of the pile plotted against the mean axial stress. In the figure the yield stress line, Euler's elastic instability curve and Rankine's combined buckling curve are plotted. The graph has a close resemblance to the observed case histories of pile foundation performance during past earthquakes, as shown in Fig. 4. 
Table 5. Performance of piles during the centrifuge tests

\begin{tabular}{|c|c|c|c|c|c|c|c|}
\hline Test ID & Pile ID & $\begin{array}{l}\text { Head mass: } \\
\text { kg }\end{array}$ & $\begin{array}{c}\text { Max load, } \\
P: \mathrm{N}\end{array}$ & $\begin{array}{l}P / A: \\
\mathrm{MPa}\end{array}$ & $L_{\mathrm{eff}}\left(L_{\mathrm{eff}} / r_{\mathrm{min}}\right.$ & $P / P_{\text {cr }}$ & Remarks \\
\hline \multirow{3}{*}{$\begin{array}{l}\text { SB-02 } \\
\text { Pile length }=160 \mathrm{~mm} \\
r_{\min }=3 \cdot 1 \mathrm{~mm} \\
A=9.7 \mathrm{~mm}^{2}\end{array}$} & 1 & 1.96 & 768 & 79 & $355 \mathrm{~mm}(114)$ & 0.97 & Failed at $40 g$ during swing-up \\
\hline & 2 & 1.56 & 642 & 65 & $350 \mathrm{~mm}(113)$ & $1 \cdot 01$ & Failed at $42 g$ during swing-up \\
\hline & 3 & $1 \cdot 26$ & 617 & 63 & $345 \mathrm{~mm}(111)$ & 0.97 & Failed during earthquake \\
\hline \multirow{3}{*}{$\begin{array}{l}\text { SB-03 } \\
\text { Pile length }=180 \mathrm{~mm} \\
r_{\min }=3 \cdot 1 \mathrm{~mm} \\
A=11 \cdot 2 \mathrm{~mm}^{2}\end{array}$} & 4 & $0 \cdot 60$ & 294 & $26 \cdot 3$ & $372 \mathrm{~mm}(120)$ & 0.5 & Did not collapse \\
\hline & 5 & 0.45 & 220 & $19 \cdot 7$ & $370 \mathrm{~mm}$ (119) & $0 \cdot 35$ & Did not collapse \\
\hline & 6 & 0.23 & 113 & $10 \cdot 1$ & $370 \mathrm{~mm}$ (119) & $0 \cdot 22$ & Did not collapse \\
\hline \multirow{3}{*}{$\begin{array}{l}\text { SB-04 } \\
\text { Pile length }=180 \mathrm{~mm} \\
r_{\min }=3 \cdot 1 \mathrm{~mm} \\
A=11 \cdot 2 \mathrm{~mm}^{2}\end{array}$} & 7 & $1 \cdot 25$ & 610 & $54 \cdot 5$ & $420 \mathrm{~mm}(135)$ & $1 \cdot 04$ & Failed during earthquake \\
\hline & 8 & 1.78 & 872 & 78 & $445 \mathrm{~mm}(144)$ & 1.48 & Failed during earthquake \\
\hline & 9 & $4 \cdot 68$ & 2249 & 201 & $90 \mathrm{~mm}(29)$ & $0 \cdot 25$ & Did not collapse \\
\hline
\end{tabular}

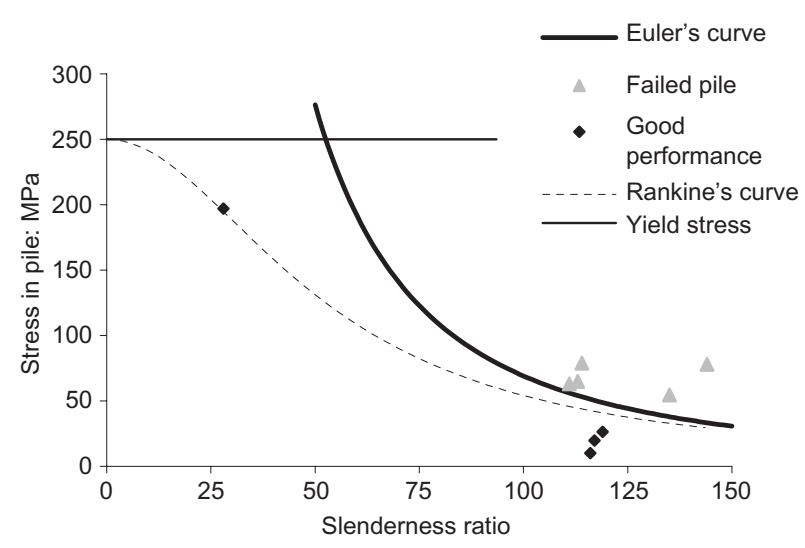

Fig. 10. Performance of piles in tests SB-02, SB-03 and SB-04

\section{Replication of mechanism}

Figure 11(a) shows the surface observation of the piles after test SB-02. Note that the heads of the piles rotated. It is quite similar to visual observations of the piled building shown in Fig. 11(b). The building is Kandla port tower in laterally spreading soil, which tilted by $15^{\circ}$ after the 2001 Bhuj earthquake (India). The pile that failed during the earthquake is shown in Fig. 11(c), and the figure shows that the hinge formed at the top third of the pile. Fig. 11(d) shows the point of hinge formation in the failure of a threestorey reinforced concrete building revealed after excavation following the 1995 Kobe earthquake. There is a similarity between the locations of hinge formation in the centrifuge test and in the aftermath of real earthquakes. This demonstrates that the pile failure mechanisms observed in the field can be replicated using dynamic centrifuge modelling. Note that the real piled buildings were in laterally spreading soil, whereas the model piles in the experiments were in level ground. Thus the centrifuge tests illustrate that buckling can be a possible failure mechanism of piles in liquefiable soil sites.

\section{Effect of axial load on pile foundation}

The present paper is intended to improve understanding of the effects of axial load on a pile during soil liquefaction, and hence experiments SB-04 and SB-05 need to be dis- cussed in more detail. Note that no inertia force was acting on the pile-head in the direction of buckling in tests SB-04 and SB-05, and hence the test results are the effects of axial load alone. Fig. 12(a) shows pile 7 partially revealed after the test, and Fig. 12(b) shows the pile after excavation was complete. In test SB-05 an identical pile was tested in the absence of soil, and Fig. 12(c) shows that pile after the test. Similar forms of buckling are shown in Fig. 13 for pile 8, and thus we can conclude that this observation is repeatable.

In both tests, the piles buckled in the transverse direction - that is, orthogonal to the direction of shaking. In test SB-04 the hinge formed about one third the way down the liquefiable soil, whereas in test SB-05 the hinge formed at the bottom third of the pile in air.

Figure 14 shows the instrumentation layout, with pore pressure transducer locations surrounding pile 8 and also in the free field. Fig. 15 shows the free field traces of excess pore pressure. Note that, as the shaking starts, the pore pressure rises in the soil, starting from the top and proceeding downwards. In every case, at a time of about $0.5 \mathrm{~s}$ in the history, or about $0.25 \mathrm{~s}$ after shaking started, the excess pore pressures $(\delta u)$ in the free field reach a plateau. Fig. 15 shows that in each case the plateau corresponds well with an estimate of the pre-existing effective vertical stress at the corresponding elevation, suggesting that $\sigma_{\mathrm{v}}^{\prime}$ had fallen to zero. Between $0.5 \mathrm{~s}$ and $1.0 \mathrm{~s}$ in Fig. 15, the pile will have lost all lateral effective stress in a progressive fashion, topdown. When this advancing front reached a critical depth $H_{\mathrm{c}}$ given by equation (5), the pile would have become elastically unstable, following equation (2).

$$
H_{\mathrm{c}}=\sqrt{\frac{\pi^{2} E I}{4 P}}
$$

This instability will cause the pile to begin to move slowly sideways, pushing the soil. At the same time, the front of zero effective stress continues to advance swiftly downwards until the whole length of the pile is unsupported by the soil grains. For pile 8, following equation (5), the critical depth $H_{\mathrm{c}}$ is estimated to be $148 \mathrm{~mm}$ from the centre of gravity of the pile-head mass, whereas the length of the pile in the liquefiable zone is $180 \mathrm{~mm}$. Thus the pile would have become unstable just before the entire length of the pile was unsupported by soil grains. 


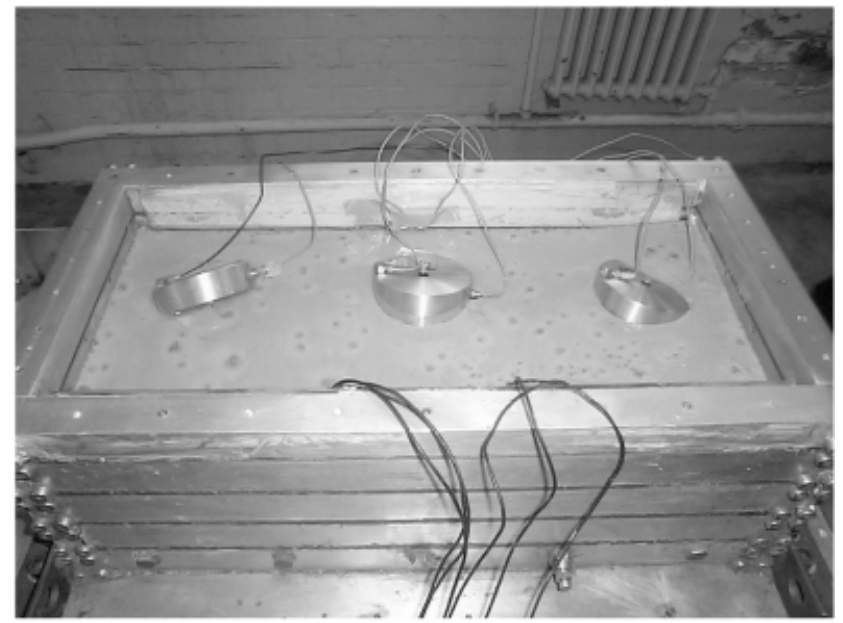

(a)

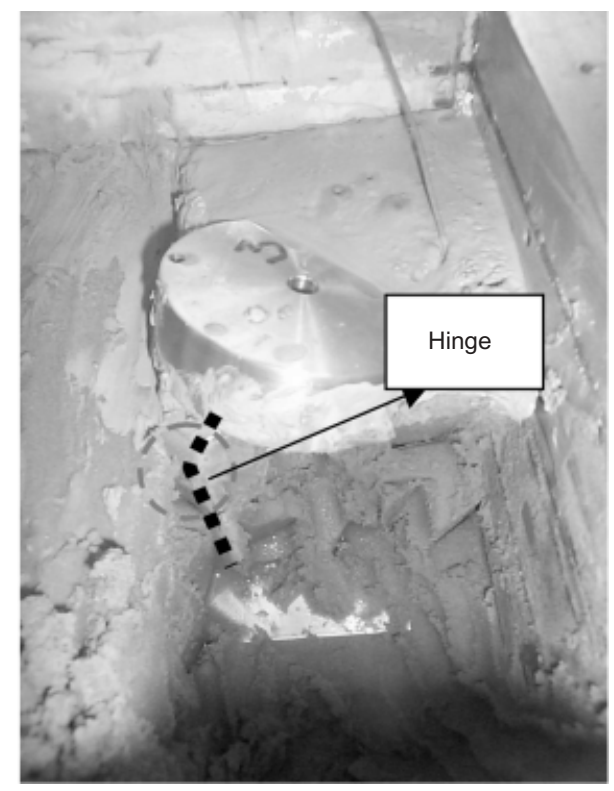

(c)

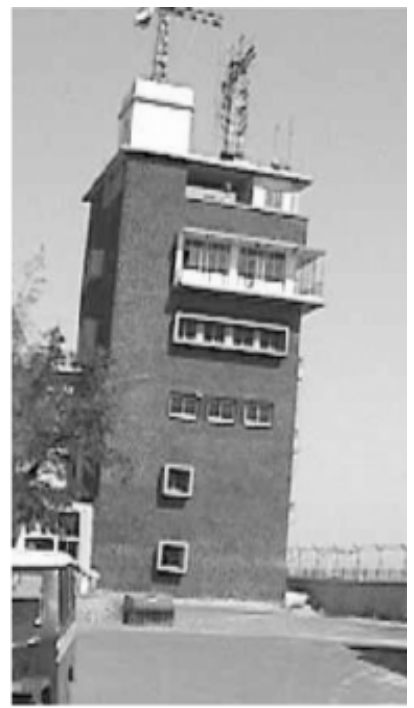

(b)

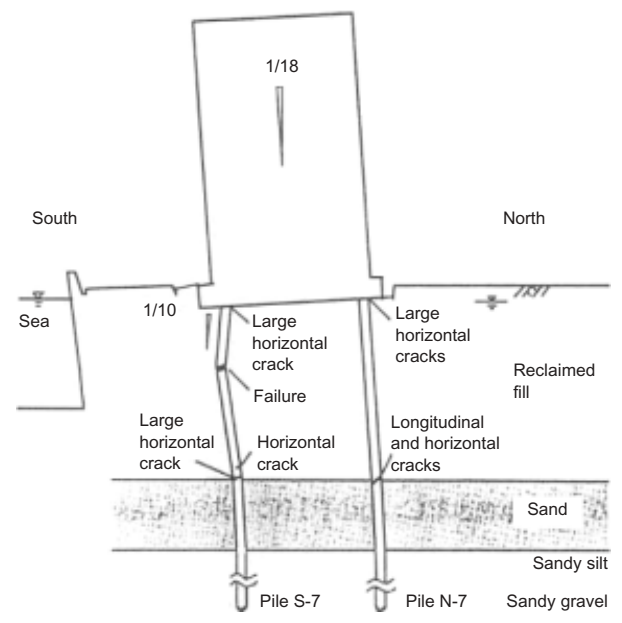

(d)

Fig. 11. (a) Piles after test SB-02; (b) Kandla tower after Bhuj earthquake (Madabhushi et al., 2001); (c) pile 3 after earthquake; (d) excavation of three-storey RC building (Tokimatsu et al., 1997)

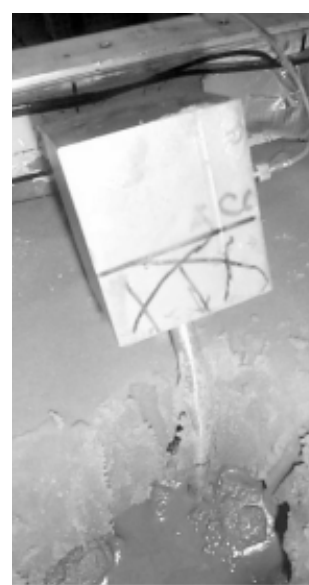

(a)

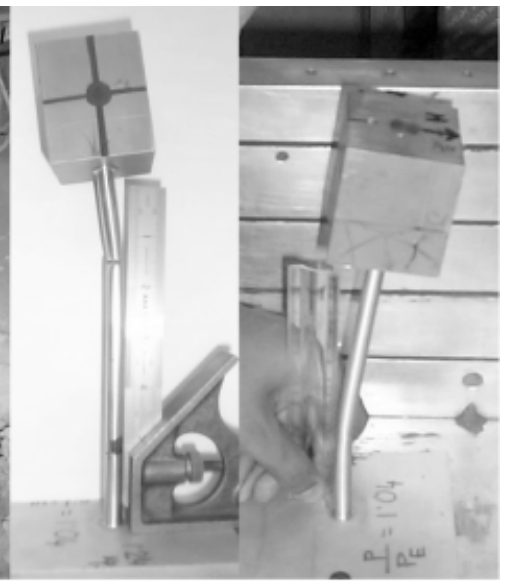

(b)

(c)
Fig. 12. (a) Mode of failure of pile 7 in test SB-04 during excavation; (b) pile 7 after excavation; (c) same pile in test SB-05
Response of the liquefied soil to pile buckling

Figure 16 compares the PPT traces at shallow depth in the near field of the pile (PPT 6260 in front of the pile, i.e. in the direction of eventual buckling; 6793 behind the pile) and the far field PPT J13. At first, up to $0.4 \mathrm{~s}$, the three PPTs record the same pressures rising to 'liquefaction'. Then, until $1.0 \mathrm{~s}$, the PPT in front of the pile shows an approximately $10 \mathrm{kPa}$ reduction of pore pressure, with additional sharper downward spikes at each earthquake cycle. The PPT behind the pile shows positive spikes, which are at first out of phase with those in front but then come into phase. The cyclic component of the PPT data behaviour is clearly related to the shaking, and therefore to motions orthogonal to the eventual direction of buckling.

By $1.0 \mathrm{~s}$ in the time record of Fig. 16 the increasing bending moments in the buckling pile must have led to sufficient plastic strain in the aluminium alloy to provoke fracture, as shown in Fig. 13(a). At this point the pile mass fell over onto the sand surface, causing the massive negative spike in PPT 6260, which was just beneath. 


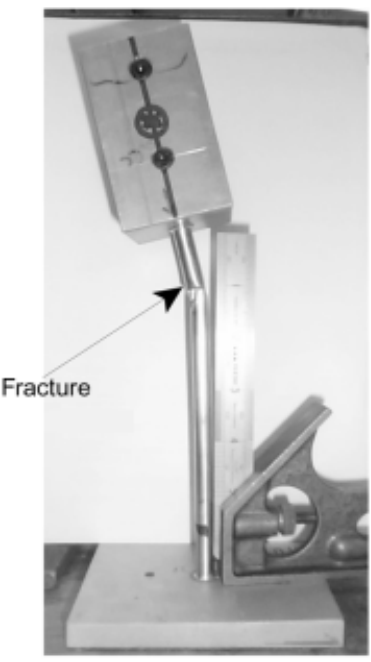

(a)

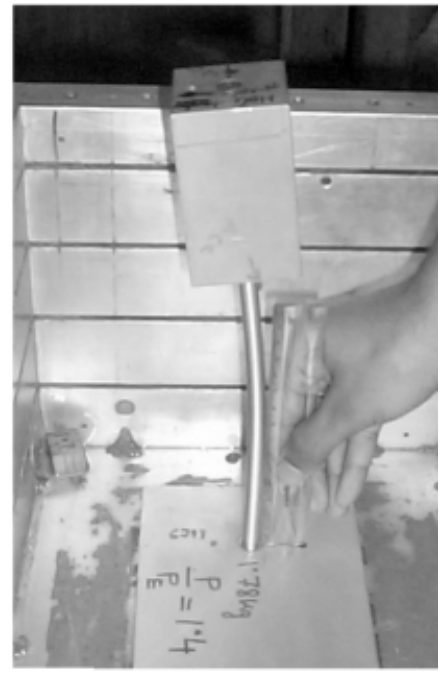

(b)

Fig. 13. (a) Mode of failure of pile 8 in test SB-04; (b) mode of failure of same pile in test SB-05

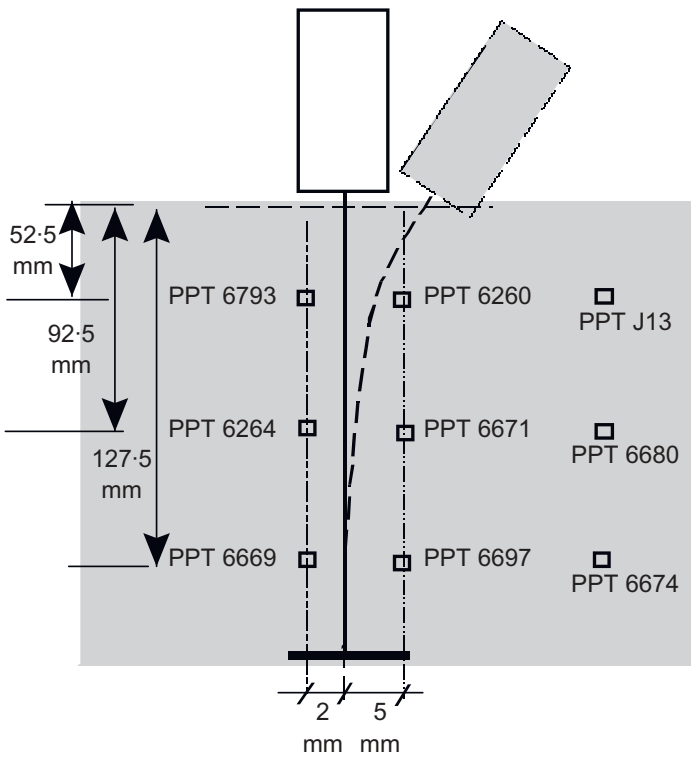

Fig. 14. Instrumentation near pile 8 in test SB-04

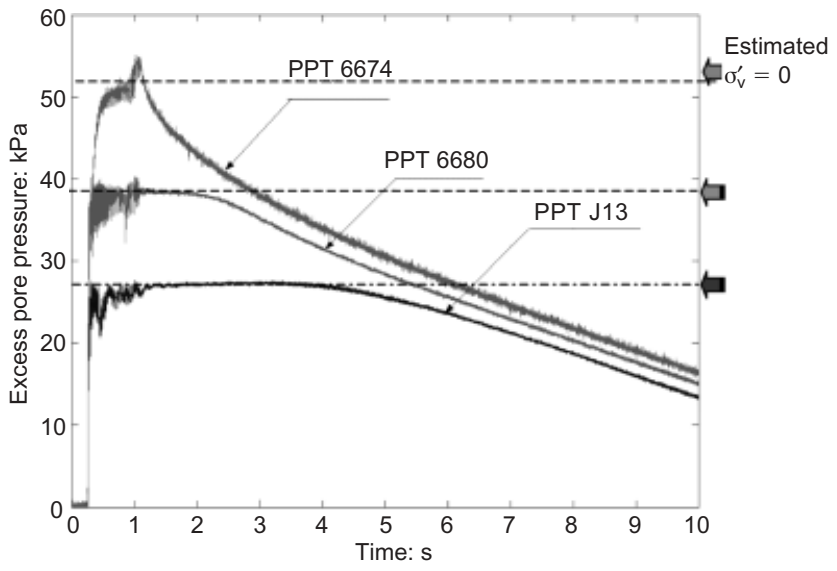

Fig. 15. Plot of PPT data in far field of pile

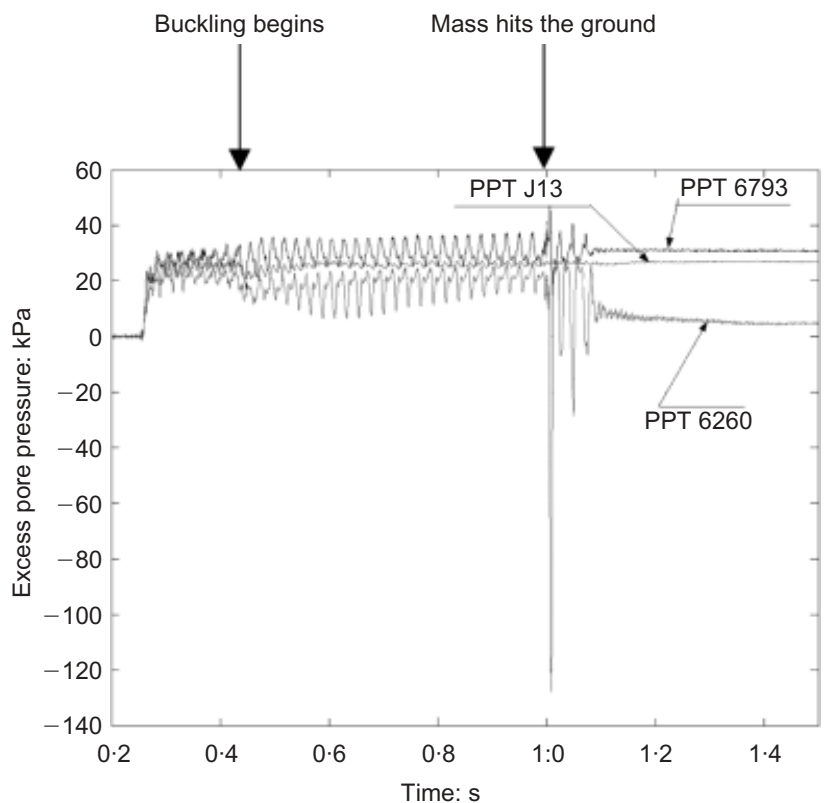

Fig. 16. Near-field and far-field pore pressure measurements at $52.5 \mathrm{~mm}$ depth

It is worth mentioning the reason for the negative pore pressure increments referred to above for PPT 6260, which was ahead of the buckling pile, and below the falling mass. Although the saturated sand was liquefied in the sense of having lost its effective stress, its voids ratio had not yet changed from its initial value. When subjected to shearing, even loose to medium dense sands will try to dilate. If suddenly sheared at constant volume, there will be compensating negative excess pore water pressures. As the pile began to buckle towards it, PPT 6260 found itself in the monotonic shear zone and responded with a negative monotonic pore pressure reduction of about $10 \mathrm{kPa}$. When the mass hit the ground, it then found itself in a zone of bearing failure, which caused a further $20 \mathrm{kPa}$ excess pore pressure reduction. Shear-induced pore pressure gradients are thought to be highly significant in understanding the details of postliquefaction phenomena. However, in this case, the data simply show that buckling of the pile began from an early point in the earthquake record when effective stresses in the surrounding soil had dropped to zero. From that point onwards the model structure was doomed to fail catastrophically.

\section{CONCLUSIONS}

A similar failure mode as for full-scale piles observed after real earthquakes in liquefiable soil has been replicated with model piles in level ground in a centrifuge. Case histories and centrifuge test results match satisfactorily with a newly proposed theory of pile failure by buckling instability. The pile can buckle and push the soil; it is not necessary to invoke lateral spreading of the soil, which pushes the pile. This instability depends on the slenderness ratio $\left(L_{\mathrm{eff}} / r_{\min }\right)$ of the pile exceeding a critical value in the liquefiable region. Once the surrounding soil has its effective stresses eliminated by an earthquake, a susceptible pile starts to buckle in the direction of least elastic stiffness. If the soil around the pile remains liquefied for long enough, the pile will suffer gross deformations and the superstructure will either tilt or deform.

Codes of practice need to include a criterion to prevent buckling of slender piles in liquefiable soils. The designer 
should first estimate the equivalent length for Euler's buckling, by considering any restraints offered by the pile cap, or the zones of embedment above or below the liquefiable soil layer. It is then necessary to select a pile section having a margin of safety against buckling under the worst credible loads.

Designers should specify fewer, large-modulus piles, in order to avoid problems with buckling due to liquefaction. Cellular foundations of contiguous, interlocked sections may also be effective.

\section{ACKNOWLEDGEMENTS}

The authors are grateful to $\mathrm{Mr}$ Chris Collison and $\mathrm{Mr}$ John Chandler for technical support in doing the tests. Discussions with Mr Allan McRobie and support from Dr S. $\mathrm{K}$. Haigh are gratefully acknowledged. The first author is thankful to Nehru Trust for Cambridge University and Cambridge Commonwealth Trust for financial help in doing the research.

\section{NOTATION}

$A$ area of the section of the pile

$I$ second moment area of the section

$L_{\text {eff }}$ effective length of the pile in liquefiable region

$L_{\text {eff }} / r_{\min }$ slenderness ratio

$P_{\text {cr }} \quad$ elastic critical load

$r_{\min }$ minimum radius of gyration

$\sigma_{\text {cr }}$ elastic critical stress

$\sigma_{\mathrm{f}}$ failure stress

$\sigma_{\mathrm{y}} \quad$ yield stress

\section{REFERENCES}

Abdoun, T. \& Dobry, R. (2002). Evaluation of pile foundation response to lateral spreading. Soil Dynamics and Earthquake Engineering 22, No. 22, 1051-1058.

Ayrton, W. E. \& Perry, J. (1886). On struts. The Engineer 62, 464.

Bergfelt, A. (1957). The axial and lateral load bearing capacity, and failure by buckling of piles in soft clay. Proc. 4th Int. Conf. Soil Mech. Found. Engng, London 2, 8-13.

Berrill, J. B., Christensen, S. A., Keenan, R. P., Okada, W. \& Pettinga, J. R. (2001). Case studies of lateral spreading forces on a piled foundation. Géotechnique 51, No. 6, 501-517.

Bhattachaya, S. (2003). Pile instability during earthquake liquifaction. $\mathrm{PhD}$ thesis, University of Cambridge, UK

Bond, A. J. (1989). Behaviour of displacement piles in overconsolidated clays. $\mathrm{PhD}$ thesis, Imperial College, London.

Brandtzaeg, A. \& Elvegaten, E. H. (1957). Buckling tests of slender steel piles in soft, quick clay. Proc. 4th Int. Conf. Soil Mech. Found. Engng, London 2, 19-23.

British Standards Institution (1985). Structural use of concrete, BS 8110. Milton Keynes: BSI

Davisson, M.T. \& Robinson, K. E. (1965). Bending and buckling of partially embedded pile. Proc. 6th Int. Conf. Soil Mech. Found. Engng, Montreal, Canada 2, 243-246.

Eurocode 7 (1997). Geotechnical design. Brussels: European Committee for Standardization.

Eurocode 8 (1998). Design provisions for earthquake resistance of structures. Part 5: Foundations, retaining structures and geotechnical aspects. Brussels: European Committee for Standardization.

Finn, W. D. L. \& Fujita, N. (2002). Piles in liquefiable soils: seismic analysis and design issues. Soil Dynamics and Earthquake Engineering 22, No. 22, 731-742.

Fleming, W. G. K., Weltman, A. J., Randolph, M. F. \& Elson, W. K. (1992). Piling engineering, 2nd edn. New York: Wiley.

Goh, S. \& O'Rourke, T. D. (1999). Limit state model for soil-pile interaction during lateral spread. Proc. 7th US-Japan Workshop on Earthquake Resistant Design of Lifeline Facilities and Countermeasures Against Soil Liquefaction, Seattle, pp. 237-260.

Golder, H. Q. \& Skipp, B. O. (1957). The buckling of piles in soft clay. Proc. 4th Int. Conf. Soil Mech. Found. Engng, London 2, 35-39.

Granholm, H. (1929). On the elastic stability of piles surrounded by a supporting medium. Proc. R. Swedish Inst. Engng Res., 1-56.

Hamada, M. (1992a). Large ground deformations and their effects on lifelines: 1964 Niigata earthquake. Case studies of liquefaction and lifelines performance during past earthquake. Technical Report NCEER-92-0001, Vol. 1, Japanese case studies. Buffalo, NY: National Centre for Earthquake Engineering Research.

Hamada, M. (1992b). Large ground deformations and their effects on lifelines: 1983 Nihonkai-Chubu earthquake. Case studies of liquefaction and lifelines performance during past earthquake. Technical Report NCEER-92-0001, Vol. 1, Japanese case studies. Buffalo, NY: National Centre for Earthquake Engineering Research.

Ishihara, K. (1997). Terzaghi oration: geotechnical aspects of the 1995 Kobe earthquake. Proceedings of 14th International Conference on Soil Mechanics and Foundation Engineering, Hamburg, 4, 2047-2073.

JRA (1996). Specification for highway bridges. Part V: Seismic design. Japanese Road Association.

Madabhushi, S. P. G., Schofield, A. N. \& Lesley, S. (1998). A new stored angular momentum based earthquake actuator. Proc. Centrifuge '98, Tokyo, 111-116.

Madabhushi, S. P. G., Patel, D. \& Haigh, S. K. (2001). Draft version of EEFIT report on observations of the 26th Jan 2001 Bhuj earthquake in India. London: Institution of Structural Engineers.

National Research Council (1985). Liquefaction of soils during earthquakes. Washington, DC: National Academic Press.

National Earthquake Hazards Reduction Program (2000). Commentary (Federal Emergency Management Agency, USA, 369) for seismic regulations for new buildings and other structures.

Rankine, W. J. M. (1866). Useful rules and tables. London.

Reddy, A. S. \& Valsangkar, A. J. (1970). Buckling of fully and partially embedded piles. J. Soil Mech. Found. Div., ASCE 96, No. SM6, 1951-1965.

Robertson, A. (1925). The strength of struts. ICE Selected Engineering Paper, 28, London: Institution of Civil Engineers.

Soga, K. (1997). Geotechnical aspects of Kobe earthquake. EEFIT Report, ch. 8. London: Institution of Structural Engineers.

Schofield, A. N. (1980). Cambridge Centrifuge operations. Twentieth Rankine Lecture. Géotechnique 30, No. 3, 227-268.

Schofield, A. N. (1981). Dynamic and earthquake geotechnical centrifuge modelling. Proceedings of the International Conference on Recent Advances in Geotechnical Earthquake Engineering and Soil Dynamics, 3, St Louis, pp. 1081-1100.

Schofield, A. N. \& Zeng, X. (1992). Design and performance of an equivalent shear beam container for earthquake centrifuge modelling, Technical Report CUED/D-Soils/TR .275, University of Cambridge.

Tan, F. S. C. (1990). Centrifuge and theoretical modelling of conical footings on sand. $\mathrm{PhD}$ thesis, Cambridge University.

Tokimatsu, K., Mizuno, H. \& Kakurai, M. (1996). Building damage associated with geotechnical problems. Soils Found., special issue (Jan), 219-234.

Tokimatsu, K., Hiroshi, O.-O., Satake, K., Shamoto, Y. \& Asaka, Y. (1997). Failure and deformation modes of piles due to liquefaction-induced lateral spreading in the 1995 Hyogoken-Nambu earthquake. J. Struct. Engng AIJ (Japan), 5, No. 495, 95-100.

Tokimatsu, K., Hiroshi, O.-O., Satake, K., Shamoto, Y. \& Asaka, Y. (1998). Effects of lateral ground movements on failure patterns of piles in the 1995 Hyogoken-Nambu earthquake. Proceedings of a speciality conference, Geotechnical Earthquake Engineering and Soil Dynamics III, ASCE Geotechnical Special Publication No. 75, pp. 1175-1186. Reston, VA: American Society of Civil Engineers. 